\title{
VIVÊNCIAS DE AGENTES COMUNITÁRIOS DE SAÚDE NA PRÁTICA CUIDATIVA EM ALEITAMENTO MATERNO
}

\author{
Community health agents of experiences in practice in \\ cuidativa breastfeeding
}

\section{RESUMO}

Objetivo: Compreender as vivências dos Agentes Comunitários de Saúde na prática cuidativa em aleitamento materno, identificar os significados do manejo clínico do aleitamento materno para os Agentes Comunitários de Saúde e verificar as ações desenvolvidas por eles às famílias que vivenciam o aleitamento materno. Métodos: Pesquisa qualitativa, convergente assistencial, fundamentada na Teoria das Representações Sociais, realizada com 05 Agentes Comunitários de Saúde num interior da Bahia durante uma oficina educativa com duração de quatro horas. Os dados foram coletados por meio do desenho estória-com-tema e aplicação de um questionário e analisados pelas propostas de Coutinho e Minayo. Como contribuição assistencial foi realizada a oficina educativa. Resultados: Os resultados evidenciaram que os significados do aleitamento materno para os Agentes Comunitários de Saúde se encontram centrados na saúde das crianças, consequentemente, suas principais ações são desenvolvidas seguindo esta vertente. Conclusão: Deste modo, sugere-se a realização de capacitações que subsidiem os Agentes Comunitários de Saúde a ampliarem a visão de cuidado no manejo clínico do aleitamento materno com enfoque na família, direcionando um olhar para a saúde mulher, comunidade e planeta e nos aspectos educativos e assistenciais.

Descritores: Aleitamento Materno; Agentes Comunitários de Saúde; Enfermagem.

\section{ABSTRACT}

Objective: To understand how the Community Health Agents develop care to families experiencing breastfeeding, identify the meanings of the clinical management of breastfeeding for Community Health Agents and verify the actions taken by the Community Health Agents to families who experience breastfeeding. Methods: A qualitative, convergent care research, the theoretical reference the Theory of Social Representations procedural approach. It was conducted with 05 community health agents in the interior of Bahia during an educational workshop lasting four hours. Data were collected through the story with theme design and application of a questionnaire, which were analyzed by the proposed Coutinho and Minayo. As healthcare contribution was held educational workshop based on the meanings verbalized by Community Health Agents. Results: The results showed that the meanings of breastfeeding for the Community Health Agents are focused on children's health, thus suasprincipais actions are developed following this strand. Conclusion: Thus, it is suggested to carry out training that support the Community Health Agents to broaden the care of vision in the clinical management of breastfeeding focusing on the family, directing a look at the woman health, community and planet and the aspects education and welfare.

Descriptors: Breastfeeding; Community Health Agents; Nursing.
Artigo Original
1) Universidade Estadual do Sudoeste da Bahia - UESB - Jequié (BA) - Brasil

2) Unidade de Saúde da Família Colônia Roberto Santos - Inhambupe (BA) - Brasil

Este artigo seguiu as normas e formatação estabelecidas pelo $5^{\circ} \mathrm{CIAIQ}$ - Congresso Ibero-Americano em Investigação Qualitativa. 


\section{INTRODUÇÃO}

Os distúrbios que incidem na infância são responsáveis por graves consequências para indivíduos e comunidades, haja vista que este é um período em que se desenvolve parte das potencialidades humanas, sendo o fator nutricional, um dos mais importantes para se obter crescimento e desenvolvimento saudáveis, já que o aleitamento materno é reconhecido mundialmente como componente essencial para a sobrevivência materno-infantil ${ }^{(1,2)}$.

Entretanto, para que o aleitamento materno aconteça é preciso não somente o conhecimento sobre sua importância, é necessário o querer/poder da nutriz, pois o desejo e o prazer em amamentar estão diretamente ligados com a produção e ejeção do leite. Além disso, as mães em processo de amamentação irão precisar de suporte para iniciar e manter o aleitamento materno. Assim, as redes sociais de apoio ganham importância na adesão à esta prática.

$\mathrm{O}$ contato e o apoio à nutriz durante o aleitamento materno por familiares, amigos e vizinhos é muito importante; além desses, outros, também exercem papel fundamental para o sucesso da lactação -, os profissionais de saúde ${ }^{(3)}$, em especial, os que atuam na Estratégia Saúde da Família (ESF), dentre eles os Agentes Comunitários de Saúde (ACS), os quais são de grande importância neste contexto, uma vez que lidam com gestantes, puérperas, nutrizes e seus familiares em processo de amamentação, apoiando-os.

No entanto, estudo realizado com nutrizes sobre a influência do ACS no aleitamento materno evidenciou que o cuidado desse ator social, ainda era incipiente, se centrando apenas nas orientações sobre a importância do leite materno para a saúde da criança, sugerindo que sejam realizados investimentos na capacitação destes profissionais, frente à sua aproximação com as nutrizes na comunidade e nos domicílios $^{(4)}$.

O ACS é o profissional que está mais próximo do cotidiano das famílias, com maior oportunidade para promover, proteger e apoiar a amamentação em famílias que vivenciam o aleitamento materno, podendo ajudar nas dificuldades, dúvidas e perspectivas dos núcleos familiares, além disso, pode solicitar à enfermeira para agir, caso tenha algum problema que ele não possa solucionar.

Diante disso, o interesse em pesquisar sobre essa temática surgiu a partir das práticas e pesquisas realizadas no projeto de extensão "Vamos amamentar, mamãe?", da Universidade Estadual do Sudoeste da Bahia, o qual vem desenvolvendo ações de promoção, proteção e apoio ao aleitamento materno na comunidade jequieense, contando com participação de discentes e docentes do Departamento de Saúde I e II. Constataram-se no desenvolvimento dessas, que as dificuldades referentes à prática do aleitamento materno são maiores do que se possam imaginar, especialmente quando as mulheres retornam para o contexto domiciliar, momento em que a família necessita de apoio e conhecimentos sobre o manejo clínico da lactação para resolver dificuldades que surgem nos primeiros dias de amamentação.

Destarte, este estudo torna-se relevante devido à importância para promoção, proteção e apoio ao aleitamento materno como práticas fundamentais para o bom desenvolvimento do ser humano que, constantemente sofre influências das redes de apoio, em especial, dos ACS. Além disso, existem poucos estudos que exploraram a influência destes atores sociais na prática do aleitamento materno no contexto familiar.

A partir deste contexto, surgiu a questão de pesquisa: Qual a vivência dos ACS na prática cuidativa do aleitamento materno? Para responder a este questionamento traçaramse como objetivos: compreender as vivências dos ACS na prática cuidativa do aleitamento materno, identificar os significados do manejo clínico do aleitamento materno para os ACS e verificar as ações desenvolvidas por eles às famílias que vivenciam o aleitamento materno.

\section{MÉTODOS}

Estudo qualitativo, baseado na pesquisa convergente assistencial (PCA), com suporte teórico da Teoria das Representações Sociais (TRS), na abordagem processual. As representações sociais (RS) são estruturas de conhecimento cognitivas, afetivas e avaliativas, advindas da relação de reciprocidade entre o indivíduo e a sociedade, orientando e organizando condutas e comunicações sociais ao facilitar o processo de informação $0^{(5)}$.

Foi realizado numa Unidade Saúde da Família (USF) num Município da Bahia no mês de junho de 2014, durante a realização de uma oficina educativa sobre amamentação. Os participantes do estudo foram 05 (cinco) ACS de duas equipes de saúde da família, atuantes no momento da coleta de dados e que aceitaram participar da pesquisa ao assinarem o Termo de Consentimento Livre e Esclarecido (TCLE). Vale destacar que as duas USF possuíam 10 (dez) ACS, entretanto, apenas cinco estavam atuando no momento da coleta de dados, uma vez que dois eram representantes de sindicato, dois estavam de licença médica e um de licençaprêmio.

A PCA iniciou-se com a aplicação da primeira técnica de coleta dos dados, o Desenho estória-com-tema, a qual consiste numa técnica projetiva, e, por ser considerada um importante método de investigação em estudos de RS, permite que o participante demonstre suas representações sem distorções do ponto de vista formal ${ }^{(6)}$. 
A técnica do desenho estória-com-tema consistiu em oferecer para os ACS uma folha de papel em branco, sem pauta, de tamanho ofício, lápis preto, canetas coloridas e borracha. Em seguida foi solicitado que eles fizessem um desenho que representassem o significado do cuidado às famílias que vivenciam a amamentação. Após a realização do desenho foi solicitado que eles contassem uma estória com princípio, meio e fim, por último que dessem um título à estória.

Em seguida, os ACS responderam ao questionário semiestruturado contendo questões abertas e fechadas referentes aos dados sóciodemográficos e ao manejo clínico da amamentação. Após apresentação dos desenhos e estórias pelos ACS, as pesquisadoras procederam discussão sobre o aleitamento materno, a partir das RS da amamentação atribuídas pelos ACS.

Os dados advindos do desenho estória-com-tema foram analisados conforme proposta de Coutinho ${ }^{(7)}$, que consistiu em observação sistemática dos desenhos e temas; seleção dos desenhos por semelhança gráficas e aproximação dos temas; leitura flutuante, recorte e categorização das unidades temáticas das estórias e análise e interpretação dos conteúdos temáticos agrupados por categorias, que após transversalização dos dados advindos do questionário, foram organizados conforme proposta de Minayo $^{(8)}$. A discussão dos resultados se fundamentou nos pressupostos da TRSe em pesquisas publicadas referentes à temática deste estudo.

A ética permeou todo o percurso deste estudo. Para tanto, foram seguidos os preceitos éticos estabelecidos pela Resolução 466 de 12 de dezembro de $2012^{(9)}$ Este estudo foi aprovado pelo Comitê de Ética em Pesquisa da UESB (CEP/UESB), sob o número de parecer 576.628, sendo, um dos subprojetos da pesquisa intitulada "O cuidado à família que vivencia a amamentação", também aprovado pelo referido Comitê sob o parecer 338.630.

\section{RESULTADOS}

A idade dos ACS variou entre 37 e 42 anos, a maioria do sexo feminino, casadas 4 (quatro), com número de filhos que variouentre 01 (um) e 02 (dois), sendo que apenas 01 (um) não foi amamentado. Todas (os) possuíam o ensino médio, apresentavam tempo de serviço como ACS entre 08 e 17 anos, já haviam participado de capacitações em aleitamento materno e foram amamentados.

\section{Representações sociais do aleitamento materno para os ACS}

Os ACS representaram a amamentação como sendo importante para a saúde da criança, estas ancorados em suas experiências pessoais, interação/relação com os (as) filhos (as) ou outras pessoas nos grupos de pertença e em conhecimentos advindos da mídia escrita e falada. Para eles, o leite materno foi considerado alimento nutritivo, saudável, natural, completo, que contém todas as vitaminas que a criança necessita, além de ser fundamental para as crianças nos primeiros anos de vida, conforme registrado a seguir:

É um processo fundamental e importantíssimo para o desenvolvimento da saúde da criança [...] (ACS 4).

É uma alimentação saudável e nutritiva (ACS 2).

Um alimento importantíssimo, completo e contém todas as vitaminas que a criança necessita (ACS 5).

Por possuir estas propriedades, o leite materno foi considerado pelos ACS como um líquido precioso e o líquido da vida, que quando rega o corpo infantil, não somente o alimenta, mas proporciona amor, um amor que floresce quando a mãe decide amamentar o filho, como mostra a figura 1 , expressa por uma árvore florida com corações.

Assim, para os ACS deste estudo, para que a criança receba todos os benefícios que o aleitamento materno proporciona para sua saúde é preciso que a mulher se dedique a esta tarefa, já que amamentar é a forma da mãe demonstrar amor, carinho e afeto pelo filho, jáque para a mulher, o ato de amamentar é um momento único e prazeroso, como destacados nos seguintes discursos:

[...] Uma forma de também de mostrar afeto-carinho, amor e dedicação. (ACS 1)

É um processo fundamental para [...] desenvolvimento da afetividade criança $x$ mãe. (ACS 4).

Timidamente a família permeou as RS dos ACS, quando eles destacaram os benefícios que a amamentação proporciona para esta rede social, ao representar, por meio do desenho estória-com-tema 02 (Figura 2) um grupo familiar feliz.

Para os ACS, a felicidade da família ocorre, pois ela está protegendo e promovendo a saúde de seus membros quando optam por alimentar os (as) filhos (as) com o leite materno. Desta forma, o aleitamento materno é um cuidado que proporciona saúde, harmonia e união familiar, favorecendo a alegria de viver.

\section{Práticas cuidativasdos ACS em aleitamento materno}

Dentre as práticas cuidativas destacadas pelos ACS estão incluídas ações educativas, assistenciais e administrativas.As ações educativas, proporcionadas pelos ACS foram centradas nas orientações sobre a importância 
do aleitamento materno para a saúde das mães e das crianças, conforme discursos abaixo:

[...] importante em todos os aspectos quanto saúde do bebê e da mãe. (ACS 3)

[...] beneficios da amamentação para o bebê e também para a mãe. (ACS 4)

Entretanto, gestantes, puérperas e mães são orientadas em seus domicílios, quase que exclusivamente, quanto à importância do leite materno para a saúde das crianças, período de oferecimento exclusivo do leite até os seis meses, não oferecer outros alimentos, que não existe leite fraco, alimentação saudável, importância do colostro como a primeira vacina e prevenção de doenças, cuidados com as mamas, higiene bucal e ser econômico, deixando de ser mencionar as demais vantagens desta prática, inclusive para a saúde da mulher, conforme pode-se confirmar nos seguintes discursos:

Que é de fundamental importância até os seis meses que a mãe amamente para que o seu bebê fique saudável, não venha gripar ou adoecer com facilidade, pois além de ser bom irá economizar em seu bolso. Explico que o colostro é um tipo de vacina importante e que não há leite fraco [...], pois sem amamentação a criança fica mais propícia a adoecer. (ACS 5)

Falo da necessidade que a criança tem de ser alimentada, que durante 6 meses não precisa dá outro alimento, pois o leite materno tem todos os nutrientes que o bebê precisa para crescer saudável.Que é uma alimentação saudável da criança e que o colostro é a primeira "vacina do bebê". (ACS 1)

Oriento a ela a não dar nenhum outro tipo de alimento ao filho só o leite materno.(ACS 2)

Falo sobre a importância do leite materno e que seu filho será uma criança saudável se for amamentado. (ACS 2)

Orientação acerca dos cuidados com a mama (fortalecimento, higienização etc). Higiene bucal do bebê. (ACS 4)

Por conseguinte, os ACS relataram que orientam não apenas as mães e gestantes, mas incluem os familiares nas ações educativas. Discorreram que o pai e a avó, são atores sociais que se encontram presentes nos domicílios e destacaram que as avós muitas vezes têm concepções diferentes daquelas estabelecidas pelo Ministério da Saúde.

Dando orientações a todos o quanto estão envolvidos com a criança e mãe. (ACS 4)

Oriento o pai, a mãe, principalmente a avó que nesse contexto muitas vezes quer fazer 'diferente' das orientações do Ministério da Saúde. (ACS 1)
Quanto às ações assistenciais, os ACS destacaram a importância de demonstrar como colocar a criança na posição correta, prática assistencial considerada essencial para ser desenvolvida durante a amamentação, dado a sua importância para prevenção dos intercorrências mamárias.

Como amamentar, colocando a criança em uma posição correta. (ACS 2)

Além de passar as informações, observar a pega da amamentação vendo se a mãe está conseguindo amamentar e se está na posição correta. (ACS 5)

Vale ressaltar que somente o ACS 4 destacou a importância de se analisar o estado psicológico da mãe antes de direcionar um cuidado em aleitamento, seja ele educativo ou assistencial.

Analisar o estado psicológico da mãe como ela está reagindo ao novo estilo de vida, se está tendo paciência ou dificuldades para amamentar. Vê as condições de cuidados da mãe com o bebê antes e depois da mama. (ACS 4)

Em outra vertente, o ACS 2, destacou a importância de orientar as mulheres a darem mais atenção, carinho e amor para os (as) filhos (as): orientando elas a darem mais atenção, amor e carinho aos filhos, com complemento e facilitação ao processo de amamentar.

Os ACS, aindadestacaramsua participação no apoio ao aleitamento materno, ao questionar os tipos de alimentos ingeridos pelas puérperas, por acreditar que eles ajudam na produção de leite materno:[...] se está se alimentando com alimentos certos para a produção de leite.(ACS 5)

Já as ações administrativas foram incluídas como um cuidado importante e imprescindível nas ações de promoção, proteção e apoio ao aleitamento materno para as famílias que vivenciam o processo de amamentação. Para tanto, os ACS citaram as atividades de identificação e cadastramento das gestantes, comunicação à supervisora para realização de visita domiciliar ao nascimento da criança e acompanhamento mensal, conforme pode ser destacado na figura 3.

Logo, os ACS são colaboradores no processo de amamentação, como destacado pelo ACS 4 no desenho estória-com-tema 04, no qual, foi destacado por ele a importância do trabalho do ACS no apoio às famílias que vivenciam o processo de amamentação e a ajuda que fornecem às mães que enfrentam dificuldades para aleitarem seus filhos, conforme demonstrado na figura 4.

\section{Dificuldades enfrentadas pelos ACS durante a prática cuidativa}

Os ACS verbalizaram que enfrentam dificuldades durante a prática cuidativa das famílias que vivenciam o 
aleitamento materno, em especial, aquelas relacionadas aos mitos e tabus presentes em todos os domicílios visitados, dentre eles, a amamentação faz as mamas caírem, leite materno é fraco, não sustenta, choro significando fome da criança e que o parto cesáreo diminui a produção do leite, como destacado nos discursos a seguir:

Sobre alguns mitos, como por exemplo o de que o seio 'cai'.(ACS 1)

Que o leite é fraco e que a criança fica com fome e que o leite não sustenta. (ACS 3)

Algumas mães quando o parto é Cesário onde ocorre uma diminuição do leite nos dias em que usou medicações elas não querem estimular a produção do leite materno querendo dar outros tipos de leite como o nan. (ACS 4)

Quando a mãe insiste em bater na tecla que o leite é fraco, pois a criança não dormiu, pois o leite não sustentou e a mesma substitui outros alimentos. (ACS 5)

Outras dificuldades encontradas pelos ACS foram a indisponibilidade das mães para amamentar devido rachaduras e dor nos mamilos e a falta de compreensão e paciência de algumas delas durante a amamentação, levando-as a substituírem precocemente oleite materno por outros alimentos.

Algumas mães se sentem indisponíveis, pois amamentar causa dor e rachaduras no seio. (ACS 1)

A falta de compreensão e paciência de algumas delas. (ACS 2)

Figura 1 - Desenho estória-com-tema 01.

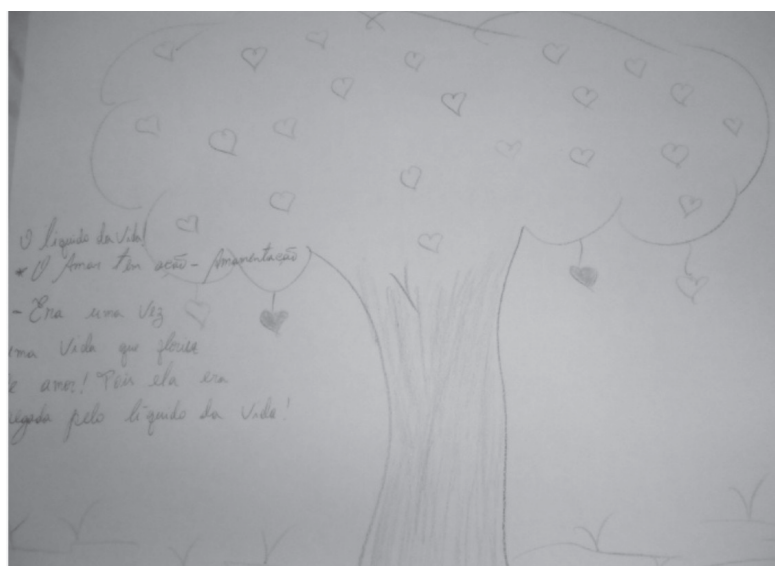

O líquido da vida! - O amor tem ação - Amamentação

Era uma vez uma vida que floriu de amor! Pois ela era regada pelo líquido da vida! (ACS 1)
Os problemas mamários tem sido uma das causas verbalizadas por um grande número de mulheres que vivenciam a amamentação, o que pode ser compreensível quando elas se sentem indispostas e impacientes, momento em que o apoio dos ACS se torna imprescindível.

\section{DISCUSSÃO}

Para gerar representações o objeto precisa ter alguma relevância cultural ou espessura social ${ }^{(10)}$. Como se pode perceber nos significantes e significados do aleitamento materno destacados pelos ACS ao cuidarem das famílias que vivenciam a amamentação, percebeu-se que este é um tema inserido no contexto social, possuindo relevância cultural, já que se encontra imbricado nas ações de saúde desenvolvidas por eles.

Os significados expressos nos discursos dos ACS, centrados na saúde da criança, têm sido discutidos em outros estudos, com a amamentação sendo representada como um ato natural de vínculo, afeto, proteção e nutrição para a criança, sendo um "momento em que a mãe se apega, dá amor e se une o(a) filho(a) ao aconchegá-lo(a) junto de si."'(11:115)

Na figura 1, quando o ACS 1 fez emergir de maneira "primitiva, concreta, em nível motor"(6:88), uma árvore florida de corações, a qual havia sido regada pelo líquido da vida -, leite materno, floriu de amor. Portanto, da mesma forma como a árvore floriu e deu bons frutos - os corações, a criança que é amamentada cresce e se desenvolve com

Figura 2 - Desenho estória-com-tema 02.

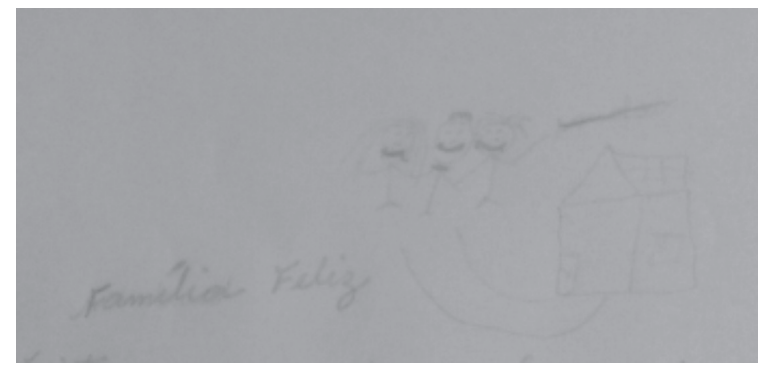

Família Feliz

Existe nessa família a alegria de viver, com uma saúde e uma harmonia, tendo uma união porque os seus problemas individuais e familiares estão sendo solucionados. Pois existe um cuidado, uma preocupação, sendo estabelecida em uma promoção e prevenção a essa família (ACS 5) 
Figura 3 - Desenho estória-com-tema 03.

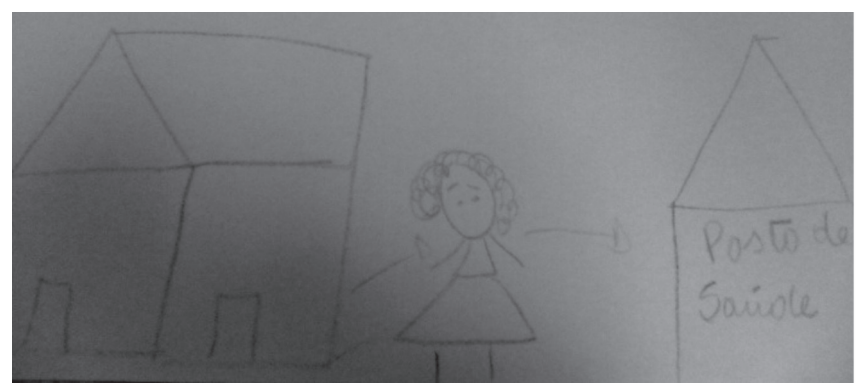

O Agente em ação

Primeiro identificar a gestante e fazer o cadastro para acompanhamento mensal. É aí um começa uma história de ajuda e companheirismo onde o a gestante começa a ter mais cuidado por parte do Agente durante a gravidez $e$ depois. (ACS 3)

saúde, amor, confiança, tranquilidade, pois recebeu o líquido da vida, o leite materno.

As RS são produzidas no campo dos fenômenos comunicacionais, sendo a comunicação social a responsável pelo modo como estas representações surgem, refletindo os objetos que estão no cotidiano das pessoas ${ }^{(12,13)}$. Assim, a ancoragem do aleitamento materno ao sentimento de amor, demonstrada na figura 1 , está vinculada diretamente às propagandas de incentivo ao aleitamento, principalmente nos anos 90 em que era visto como ato motivado acima de tudo pelo amor materno ${ }^{(14)}$.

Alguns estudos ressaltam a importância da participação da família no processo de amamentação, exercendo forte influência sobre esta prática ${ }^{(2,3)}$. participando de maneira direta nas questões relacionadas ao ato de amamentar/ alimentar as crianças, conforme importância destacada à família neste processo nos discursos dos ACS e objetivada no desenho-estória com tema do ACS 02, figura 2.

$\mathrm{O}$ sucesso da amamentação depende do apoio e orientação que as mulheres e suas famílias recebem dos profissionais de saúde nas consultas durante o pré-natal, parto e puerpério nas unidades básicas de saúde, no hospital e nos domicílios. Desse modo, no contexto deste estudo, os ACS têm papel preponderante nas ações de promoção, proteção e apoio ao aleitamento materno, especialmente nos domicílios.

Assim, "por residirem na própria comunidade em que trabalham, os ACS conhecem profundamente as crenças, os valores, a linguagem, os perigos e as oportunidades da realidade em que vivem"(15:413), o que possibilita uma intervenção mais precisa nas reais necessidades das famílias sob sua responsabilidade, em especial aquelas que dizem respeito ao processo de amamentação.
Figura 4: Desenho estória-com-tema 04

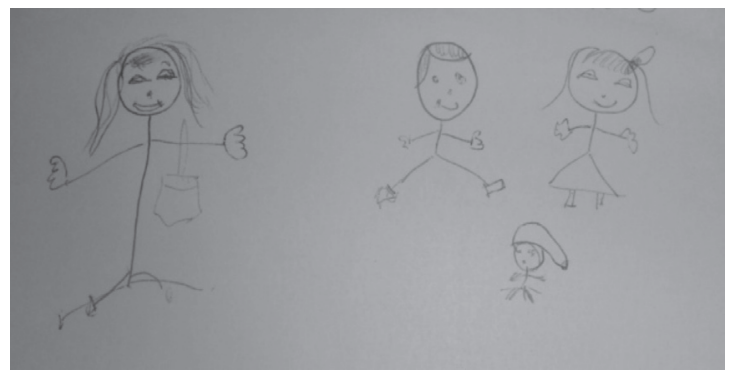

O Agente como colaborador no processo do aleitamento materno

O trabalho do Agente Comunitário representa um grande apoio às familias, levando informações que ajudam a incentivar e apoiar nesse processo primário da alimentação do bebê, e ajudam as mães com dificuldades na amamentação visto que é um processo prazeroso e não para se tornar doloroso. (ACS 4)

Diversos estudos apontam a importância de outras pessoas no incentivo ao aleitamento materno, como a família, tendo participação relevante no que se refere aos cuidados aos seus membros, sendo as mulheres-avós as principais cuidadoras e responsáveis por transmitir seus conhecimentos $^{(16)}$ o pai, o qual também pode exercer grande influência, ${ }^{(3)}$ bem como os amigos e vizinhos ${ }^{(17)}$.

Neste estudo, os ACS ancoraram os significados do cuidado às famílias que vivenciam o aleitamento materno centrado nas ações educativas, assistenciais e administrativas.

No que se refere às ações educativas, os ACS centralizaram suas orientações nos benefícios que o aleitamento materno proporciona para a saúde da criança. No entanto, apesar da amamentação possuir benefícios para o crescimento e desenvolvimento saudáveis das crianças do ponto de vista biopsicossocial, ela também, é importante para saúde da mulher, família, sociedade e planeta, por ser considerado um ato ecológico ${ }^{(2)}$.

Além disso, a alimentação e nutrição são hábitos essenciais para a promoção e proteção da saúde, pois gera crescimento e desenvolvimento humano com qualidade de vida e cidadania ${ }^{(18)}$. Porém, foi a partir de 1980 que o aleitamento materno exclusivo até os seis meses ganhou forte destaque e incentivo, devido aos relatos de que a introdução de outros alimentos neste período poderia resultar em prejuízos à saúde da criança ${ }^{(19)}$.

No que se refere às práticas assistências, a orientação e a ajuda para manter a criança em posição e a pega corretas resultam em uma amamentação de sucesso, pois, caso estejam incorretas, interferem na produção do leite, além de provocar problemas mamários, desestímulo materno para amamentar e introdução precoce de outros alimentos ${ }^{(2)}$. Por 
isso a importância de orientação e apoio corretos acarretará em benefícios não apenas para a criança, mas, para todos os envolvidos no processo de lactação, em especial a mulher, que se sentirá mais segura e confiante no seu potencial para amamentar.

Destarte, tanto as informações, quanto o apoio são de grande relevância na promoção, proteção e apoio ao aleitamento materno, pois aumenta a confiança da mãe no que diz respeito ao poder do leite materno para a saúde da criança, evitando a introdução precoce de alimentos, consequentemente, o desmame precoce.

No entanto, torna-se imprescindível que os ACS informem também que a amamentação pode ser continuada até os dois anos ou mais, a depender do desejo da nutriz. Assim, como a importância da introdução de alimentos saudáveis a partir do sexto mês de vida criança. Isto porque, em nossa prática cotidiana vem sendo percebido que muitas mulheres, referem que vão amamentar somente até o sexto mês de vida da criança, porque alguns profissionais de saúde vêm fornecendo apenas esta orientação, apesar do leite materno continuar "sendo importante fonte de nutrientes no segundo ano de vida"(1:13).

É importante que o profissional de enfermagem, ainda no pré-natal, avalie a predisposição emocional da gestante e de seu parceiro para a amamentação, bem como costumes, receios e experiências anteriores ou a oportunidade de observar a amamentação no seu ciclo familiar ${ }^{(20)}$. Vamos além, e acrescentamos que este cuidado deve ser repetido no alojamento conjunto, nos serviços de atenção à saúde da criança e nas visitas domiciliares, conforme destacado por um dos ACS deste estudo.

$\mathrm{O}$ apoio à amamentação deve ser iniciado logo após o parto, devendo ser de maneira adequada, respeitando o desejo de privacidade da mãe, encorajando-a a amamentar com frequência ${ }^{(1)}$, uma vez que, quanto mais cedo a mãe for apoiada/orientada, maior vai ser o sentimento de acolhimento e segurança, favorecendo as chances de uma amamentação de sucesso.

Além disso, cabe ao profissional de saúde averiguar quais pessoas estarão mais próximas das famílias em processo de aleitamento materno e orientá-las quanto a importância de sua ajuda. Diversos estudos apontam a importância de outras pessoas no incentivo ao aleitamento materno, como a família, tendo participação relevante no que se refere ao cuidado a seus membros, sendo as mulheresavós as principais cuidadoras e responsáveis por transmitir seus conhecimentos, inclusive sobre a amamentação ${ }^{(16)}$. O pai, também, pode exercer grande influência ${ }^{(3)}$, bem como os amigos e vizinhos ${ }^{(17)}$.

Pois, a forma como a sociedade vê a mulher e seus papeis sociais pode leva-la culpabilização pelo não sucesso ou não da amamentação.A atribuição da responsabilidade apenas na mulher-mãe diante do processo de amamentação pode gerar o sentimento de culpa, caso tenha passado por momentos de dificuldades em experiências anteriores com o aleitamento materno, levando-a a acreditar na sua "incapacidade de exercer completamente seu dever de boa mãe"(21: 565).

O ACS em meio a uma equipe multiprofissional encontra-se em uma situação privilegiada para a realização de ações educativas, contudo deve ser capacitado para tal $^{(22,23)}$, de maneira que possa lidar com famílias em processo de amamentação, tornando-as mais confiantes.

Outra importante prática para promoção, proteção e apoio ao aleitamento materno, destacada pelos ACS, foi a administrativa, considerada por eles como o primeiro passo para identificação das famílias que vivenciam ou vivenciarão a amamentação, conforme pode ser visto no Desenho estória-com-tema 03, figura 3.

No que diz respeito às dificuldades encontradas na prática de cuidados dos ACS às famílias que vivenciam a amamentação, a presença dos mitos, tabus e crenças foram destacadas por eles como as que influenciam a percepção das famílias sobre o aleitamento materno, o que vem interferindo no desenvolvimento de suas práticas educativas e assistenciais. Porém, a amamentação é um ato fortemente influenciado pelo convívio da mãe-nutriz com a sociedade ${ }^{(3,24)}$, a qual está regida por normas e valores sociais que precisam ser ressignificados quando interferem na manutenção da saúde humana, que neste estudo é a amamentação.

Em um estudo mais recente com ACS, mostrou-se que uma das maiores dificuldades enfrentadas no domić́lio estão em mudar os hábitos de uma família, tornando o reconhecimento de suas orientações quase que incipientes, e que para alcançar os objetivos é preciso estabelecer um vínculo com a comunidade ${ }^{(25)}$, confirmando assim os achados encontrados neste estudo.

Sendo assim, "os ACS precisam promover, proteger e apoiar o aleitamento materno, preparando as famílias, não somente no que se refere ao quesito técnico, mas, sobretudo emocional, já que o sucesso deste ato não depende apenas da mulher" (26:354), mas, do apoio que ela receberá de sua rede social, com destaque para a equipe de saúde, na qual o ACS está inserido.

\section{CONSIDERAÇÕES FINAIS}

Evidenciou-se que os ACS desenvolvem o cuidado às famílias em processo de amamentação, a partir dos significados que este ato tem para eles, como sendo elemento importante para a saúde da criança, ancorado em 
suas experiências vividas na relação/interação interpessoal em seu ambiente familiar e de trabalho.

Apesar do estudo ter demonstrado que as ações desenvolvidas pelos ACS às famílias que vivenciam a amamentação ainda se encontram centradas nas crianças, haja vista que, eles não ressaltaram os benefícios da amamentação em sua completude, embora elenquem algumas direcionadas para as mães, eles possuem papel fundamental por serem agentes colaboradores para promoção, proteção e apoio ao aleitamento materno. Entretanto, eles precisam de suporte dos demais membros da equipe de saúde, em especial da(o) enfermeira(o) para capacitá-los no desenvolvimento de práticas educativas, assistenciais e administrativas, já que estas foram citadas pelos ACS deste estudo, como as que fazem parte de seu cotidiano de cuidado às famílias que vivenciam o aleitamento materno.

Os ACS destacaram que enfrentam dificuldades diante das situações encontradas nos domicílios, em especial, com conhecimentos pré-estabelecidos pelas famílias, como os mitos e tabus do leite fraco, pouco, choro e flacidez mamária. A busca de resolutividade dessas dificuldades se mostrou incipiente, confirmando a necessidade de capacitações constantes voltadas para o manejo clínico da amamentação.

A limitação deste estudo está relacionada ao número reduzido de ACS como participantes da pesquisa. No entanto, a divulgação destes resultados pode estimular pesquisadores para maior investigação/exploração dos cuidados realizados por eles às famílias que vivenciam o aleitamento materno no contexto domiciliar, para que sejam elucidadas maneiras de melhor instrumentalizá-los a lidarem com as questões que permeiam a amamentação.

A oficina realizada pelos pesquisadores proporcionou uma discussão proveitosa, haja vista que contribuiu para sanar dúvidas expressas pelos ACS no que concerne ao manejo clínico da amamentação. Além disso, foi um dos momentos em que não houve apenas uma coleta de dados, mas houve um cuidado importante para os ACS, o que transformou este estudo em uma pesquisa convergente assistencial.

\section{REFERÊNCIAS}

1. Brasil. Ministério da Saúde. Secretaria de Atenção à Saúde. Departamento de Ações Programáticas e Estratégicas. Além da sobrevivência: práticas integradas de atenção ao parto, benéficas para a nutrição e a saúde de mães e crianças / Ministério da Saúde, Secretaria de Atenção à Saúde, Área Técnica de Saúde da Criança e Aleitamento Materno. - Brasília: Ministério da Saúde, 2011. 50p.: il. - (Série F. Comunicação e Educação em Saúde)
2. Brasil. Ministério da Saúde. Secretaria de Atenção à Saúde. Departamento de Atenção Básica. Saúde da criança: nutrição infantil: aleitamento materno e alimentação complementar / Ministério da Saúde, Secretaria de Atenção à Saúde, Departamento de Atenção Básica. - Brasília: Editora do Ministério da Saúde, 2015. 112 p.: il. - (Série A. Normas e Manuais Técnicos) (Cadernos de Atenção Básica, n. 23)

3. Marques ES, Cotta RMM, Magalhães KA, Sant'Ana LFR, Gomes AP, Batista R.S. A influência da rede social da nutriz no aleitamento materno: o papel estratégico dos familiares e dos profissionais de saúde. Ciência \& Saúde Coletiva. 2010;15(Supl. 1):1391-1400.

4. Dalaqua EPS. Influência do agente comunitário de saúde no aleitamento materno. Trabalho de Conclusão de Curso [Graduação]. Jequié: Universidade Estadual do Sudoeste da Bahia; 2013.

5. Jodelet D. Representações sociais: um domínio em expansão. In: Jodelet D, organizadora. As Representações sociais. Rio de Janeiro: UERJ; 2001.

6. Fonseca AA, Coutinho MPL. Depressão em adultos jovens: Representações Sociais dos estudantes de Psicologia. In: Coutinho MPL, Saldanha AAW. (Orgs). Representação social e práticas de pesquisa. João Pessoa: Editora Universitária/UFPB; 2005.

7. Coutinho MPL. Uso de técnicas projetivas na apreensão das representações sociais da sintomatologia da depressão infantil. Tese [Doutorado]. São Paulo: Instituto de Psicologia da Universidade de São Paulo; 2001.

8. Minayo MCS. O Desafio do conhecimento: pesquisa qualitativa em saúde. Maria Cecília de Souza Minayo. 12. Ed. São Paulo: Hucitec; 2010.

9. Brasil. Resolução n ${ }^{\circ} 466$ do Conselho Nacional de Saúde, de 12 de dezembro de 2012. Brasília: Ministério da Saúde; 2012.

10. Sá CPA. Construção do objeto de pesquisa em representações sociais. $1^{\mathrm{a}}$ ed. Rio de Janeiro: EdUERJ; 1998.

11. Teixeira MA. Soropositividade de mulheres para os vírus HIV e HTLV: significados do contágio do leite materno. Tese [Doutorado]. Salvador: Escola de Enfermagem, Universidade Federal da Bahia; 2009.

12. Nóbrega SM. Sobre a Teoria das Representações Sociais In: Moreira ASP. (org) Representações sociais: teoria e prática. João Pessoa: Universitária/UFPB; 2001. 
13. Barros APR, Coutinho MPL. Depressão na adolescência: Representações sociais. In: Coutinho MPL, Saldanha AAW. (Orgs). Representação social e práticas de pesquisa. João Pessoa: Editora Universitária/ UFPB; 2005.

14. Almeida, JAG, Novak FR. Amamentação: um híbrido natureza-cultura. Jornal de Pediatria, Rio de Janeiro,2004; 80(5):119-125.

15. Pereira IC, Oliveira MAC. O trabalho do agente comunitário na promoção da saúde: revisão integrativa da literatura. Revista Brasileira de Enfermagem, Brasília 2013; 66(3):412-9.

16. Teixeira MA, Nitschke RG, Silva LWS. A prática da amamentação no cotidiano familiar-um contexto intergeracional: influência das mulheres-avós. Revista Temática Kairós Gerontologia, São Paulo, 2011; 14(3):205-221.

17. Teixeira MA; Ribeiro LVB. As duas faces de uma mesma moeda: significados da amamentação para mães-nutrizes e suas amigas e/ou vizinhas. Revista de Saúde Pública. 2014;7(1):48-63.

18. Brasil. Ministério da Saúde. Política Nacional de Alimentação e Nutrição. Brasília: Ministério da Saúde, 2012. (Série B. Textos Básicos de Saúde)

19. Carvalho MR, Tavares LAM. Amamentação: bases científicas. $3^{\text {a }}$ Ed. Rio de Janeiro: Guanabara Koogan; 2010.

20. TamazRN. Atuação de enfermagem. In: Carvalho MR, Tavares LAM. Amamentação: bases científicas. $3^{\text {a }} \mathrm{Ed}$. Rio de Janeiro: Guanabara Koogan; 2010.

21. Marques ES, Cotta RMM, Araújo RMA. Representações sociais de mulheres que amamentam sobre a amamentação e o uso de chupeta. Revista Brasileira de Enfermagem. Brasília, 2009; 62(4): 562-9.
22. Machado MCHS, Oliveira JS, Parada CMGL, Venâncio SI, Tonete VLP, Carvalhaes MABL. Avaliação de intervenção educativa sobre aleitamento materno dirigida a agentes comunitários de saúde. Revista Brasileira de Saúde Materno Infantil. Recife, 2010; 10(4):459-468.

23. Santos MG, Ceretta LB, Schwalm MT, Dagostim VS, Soratto MT. Desafios enfrentados pelos agentes comunitários de saúde na estratégia saúde da família. Revista Inova Saúde. Criciúma, 20151; 4(1):26-46.

24. Rapoport A, Piccinini CA. Apoio social e experiência da maternidade. Revista Brasileira de Crescimento e Desenvolvimento Humano. 2006;16:85-96.

25. Silva ASR, Neto FRGX, Teófilo TJS. Visita ao lar na estratégia saúde da família por agentes comunitários de saúde. Essentia. Sobral, 2015;16(esp.):140-155.

26. Araujo VM, Teixeira MA, Ribeiro VM, Araújo RT, Lima JMD, Santos RB.Cuidado dos Agentes Comunitários de Saúde às famílias que vivenciam o aleitamento materno.Atas CIAIQ2016. Investigação Qualitativa em Saúde//Investigación Cualitativa em Salud//Volume 2: 384-356.

\section{Endereço para correspondência:}

Marizete Argolo Teixeira

Av. José Moreira Sobrinho, $\mathrm{s} / \mathrm{n}$

Bairro: Jequieziho

CEP 45206-190 - Jequié - BA - Brasil

E-mail: marizete88@yahoo.com.br. 